\title{
ACTA BIOETHICA: EXPANSIÓN DE SU ÁMBITO TEMÁTICO
}

Fernando Lolas ${ }^{1}$

Este número de Acta Bioethica se publica con apoyo del Fondo de Publicaciones Científicas de CONICYT y recoge ponencias presentadas en simposios cuya temática perseguía ampliar el ámbito temático de esta revista.

Desde sus comienzos, el área de discurso conocida como Bioética se ha centrado en asuntos relacionados con la investigación biológica y médica. Aunque los pioneros, Fritz Jahr y Van Rensselaer Potter, destacaron dimensiones adicionales, relacionadas con el cuidado del ambiente, con el comportamiento de las personas en relación a la supervivencia de la especie humana y con materias que bien podrían considerarse en el campo de la ética social, la influencia de la literatura anglosajona en los últimos decenios no consideró en forma especial estas áreas. Ello se ha visto reflejado en el tipo y la orientación de los artículos sometidos a la consideración del comité editorial. De allí la importancia de destacar, mediante el estímulo que significó la realización de seminarios de amplia temática, que tales temas encuentran ahora un lugar especial en este número. De este modo, se encuentran en esta edición contribuciones dedicadas al tema ambiental, la ética global, el importante tema del género, el impacto de los alimentos transgénicos y consideraciones sobre educación que exceden el campo de lo estrictamente biomédico.

En la sección "Interfaces", que recoge aquellos trabajos no directamente relacionados con el foco central de cada número temático, se incluyen consideraciones sobre los procesos deliberativos en los comités de ética, educación en bioética y reflexiones sobre consentimiento informado en la práctica forense.

Persiste como un desafío hacia el futuro que la reflexión bioética sea enfocada como lo que realmente es, un proceso dialógico que contribuye a la toma de decisiones frente a dilemas que plantean la ciencia y la tecnología aplicadas a los asuntos que afectan a las personas en diversos ámbitos. El Centro Interdisciplinario de Estudios en Bioética de la Universidad de Chile, bajo cuya responsabilidad se edita Acta Bioethica, contribuye de este modo a mantener un clima de pluralismo en temática y enfoque que han convertido a esta publicación en referente necesario para estudiosos de muy diversas disciplinas. Esta labor, iniciada hace ya más de una década, ha recibido el apoyo entusiasta de autores de todo el mundo y se magnifica por el buen índice de impacto alcanzado por la publicación, indexada en las más importantes bases de datos, tanto en ciencias biomédicas como en ciencias sociales y humanidades.

Este número contiene, como es habitual, recensiones de publicaciones y noticias sobre artículos y libros de interés general, que sin duda contribuyen a realzar la utilidad de esta publicación, que recoge artículos en castellano, portugués e inglés.

Como siempre, la comunidad bioética apreciará la excelente labor del comité de pares evaluadores y el trabajo minucioso del editor, Álvaro Quezada.

\footnotetext{
${ }^{1}$ Centro Interdisciplinario de Estudios en Bioética, Universidad de Chile, Chile Correspondencia: flolas@u.uchile.cl
} 